\title{
DOS NOVELAS SOBRE LA INQUISICIÓN AMERICANA PARA REINVENTAR LA INDEPENDENCIA
}

\author{
José Carlos Rovira \\ Universidad de Alicante
}

\begin{abstract}
Resumen: Se plantea, a través de un recorrido sobre la narrativa de la Inquisición, el sentido de dos novelas del siglo XIX (El inquisidor mayor, de Manuel Bilbao, y Memorias de un impostor, de Vicente Riva Palacio), en relación a la Independencia, que es anticipada a través de relatos que, centrados en los siglos XVII y XVIII, y basados en documentación procedente de los archivos del Santo Oficio, sobreabundan sobre las ideas de algunos reos como precursoras de los procesos independentistas: la ampliación ideológica consistió en acomodar, modificar, tergiversar anacrónicamente incluso, en una estrategia narrativa de reinvención de la historia.
\end{abstract}

Palabras clave: Inquisición, Independencia, narrativa, reinvención, historia.

Abstract: This study is based on a narrative tour of the Inquisition, the setting of two novels written in the 19th century (El inquisidor mayor, by Manuel Bilbao, and Memorias de un impostor, by Vicente Riva Palacio) in relation to the issue of Independence. This issue is anticipated through stories from the $17^{\text {th }}$ and 18th centuries, as well as from documents from the archives of the Inquisition regarding the pro-independence ideas of some prisoners. The ideological expansion consists of accommodation, modification, and even anachronistic distortion in the narrative strategy which reinvents history.

Keywords: Inquisition, independence, narrative, reinvention, history.

\section{Inquisición e Independencia}

Hay una imagen duradera de los tribunales del Santo Oficio en la América independiente, determinada porque formaron parte del poder colonial y con él fueron derrumbados en los procesos que se iniciaron en $1810 \mathrm{y}$ se consumaron en los decenios siguientes. Hay abundante literatura histórica americana sobre este derrumbe desde el momento en el que, en 1813, las Cortes de Cádiz realizaron la primera abolición de la Inquisición en todos los territorios de España, incluidos los de ultramar; desde 1820 también, tras la primera restitución de Fernando VII en 1914 y el inicio abolicionista del trienio liberal, junto a la consecución de las primeras independencias. Los tiempos de las emancipaciones 
americanas marcaron los enclaves principales de actuación del Santo Oficio (México, Lima, Cartagena de Indias y espacios dependientes) de acontecimientos entrelazados con los mismos procesos de soberanía. Está el caso esencial de México, donde las figuras iniciales y principales de la Independencia fueron perseguidas por el Santo Tribunal en aras también de fijar los objetivos políticos, los del poder virreinal, de su actuación. Los procesos contra Hidalgo y Morelos forman el entramado principal de esta persecución, junto al acecho duradero a Fray Servando Teresa de Mier; episodios suficientemente reconstruidos y conocidos que enlazan la institución directamente con la Independencia, contra su desarrollo ${ }^{1}$.

En un espacio geográfico más amplio, tras las independencias y en el tiempo preparatorio de las mismas, surgió con fuerza la denuncia contra la Inquisición en el terreno ideológico. La voz de los libertadores había clamado contra la institución desde muchos años antes. Francisco Miranda, en 1799, en su "Consejo de un viejo sudamericano a un joven compatriota al regresar de Inglaterra a su país" 2 , termina con la solicitud: "Leed este papel todos los días, durante vuestra navegación, y destruidlo en seguida. No olvidéis ni la Inquisición, ni sus espías, ni sus sótanos, ni sus suplicios". Miranda había tenido, en sus periplos libertadores, suficientes problemas con la Inquisición para saber bien lo que decía ${ }^{3}$.

En la figura esencial de Simón Bolívar, en su proyecto civil, no faltan las referencias directas, como en su "Discurso al Congreso Constituyente sobre el proyecto de Constitución para Bolivía”, del 26 de mayo de 1826, cuando sentenciaba defendiendo la libertad de conciencia: “’podrá un Estado regir la conciencia de los súbditos, velar sobre el cumplimiento de las leyes religiosas y dar el premio o el castigo, cuando los tribunales están en el cielo, y cuando Dios es el juez? La Inquisición solamente sería capaz de reemplazarlas en este mundo. ¿Volverá la Inquisición con sus teas incendiarias? La religión es la ley de la conciencia"4.

Acuñada la valoración muy negativa junto a la del mundo colonial, que había tenido en la Inquisición una de sus más violentas expresiones represivas, un auténtico programa de confrontación y debate surge desde la Independencia y adquiere en la novela un testimonio literario que tendrá sin embargo limitaciones estéticas importantes.

1 Un resumen de la persecución a Hidalgo, Morelos y Fray Servando, en J. T. Medina, Historia del Tribunal del Santo Oficio de la Inquisición en México, ampliada por J. Jiménez Rueda, México, Ed. Fuente Cultural, 1952 (1ª ed. 1905), 351-368.

$2 \mathrm{http} / / /$ www.bernardoohiggins.cl/institutoohdocumentos.html (consultado 8/9/2011)

3 Sobre la larga trayectoria de Miranda ante la Inquisición, cf. R. Olaechea, "Francisco Miranda y la Inquisición española: el Santo Oficio como instrumento de la política de Estado", C.I.H. Brocar, $\mathrm{n}^{\circ} 13,1987,29-56$.

${ }^{4} \mathrm{http} / / /$ www.ensayistas.org/antologia/XIXA/bolivar/bolivia.htm (consultado 8/9/2011) 


\section{La narrativa sobre la inquisición}

Tardó en aparecer, como ocurrió con casi toda la narrativa, el tema inquisitorial en la novela tras las independencias. No ocurrió así con poemas, que aparecieron al filo de los procesos revolucionarios y de la abolición del Santo Oficio, pero casi ninguno de ellos es más que una débil anécdota para la historia literaria.

Una novela breve, El Inquisidor de México, de José Joaquín Pesado5 , inició en 1838 el motivo en la narrativa. Hay en ella en cualquier caso una indicación eficaz de lo que van a ser los elementos más frecuentes que integran este tipo de obras: judíos perseguidos por el Tribunal, la figura severa del inquisidor, la delación por venganza, los interrogatorios de los acusados, la recreación del Auto de fe, el castigo en la hoguera, son elementos que se combinan en las obras del período. En la novela de Pesado, tras la delación contra una mujer, Sara de Córdova, realizada por un pretendiente despechado, que arrastra también al marido de ella, aparece un aporte de intriga con la revelación por un misterioso familiar de que Sara es hija del inquisidor general Domingo Ruiz de Guevara, quien la salvará in extremis cuando ya está en la hoguera, aunque la mujer morirá al final por las heridas recibidas en el tormento y el fuego, tras convertirse al cristianismo.

José Joaquín Pesado tiene el mérito, en cualquier caso, de haber iniciado la narrativa sobre la Inquisición, junto a su curiosa recopilación poética Los aztecas, en 1851, que fue recreación, incluso creación propia con marcado acento de clasicidad castellana, de motivos náhuatl a los que llegó por Faustino Galicia Chimalpopoca, que le ayudaba a entenderlos y, en su caso, a traducirlos. Pesado en la actualidad, al margen de su discutible valor literario, tiene el mérito de ser el iniciador tras la Independencia de dos temas esenciales para la cultura de la misma: la novela inquisitorial y la primera recopilación de motivos basados en los Cantares mexicanos.

Siguen otras obras, aparte de las dos que vamos a tratar aquí, construyendo en el siglo XIX la narrativa basada en la Inquisición: en México, junto a las de Vicente Riva Palacio que reseñaré más adelante, apareció La hija del judío 6 , que Justo Sierra O'Reilly anticipó en folletín entre noviembre de 1848 y octubre de 1851, y apareció en volumen en 1874; también un hereje y un musulmán ${ }^{7}$ de José Pascual Almazán, aparecida en 1870; en Perú, también en 1870, La novia del hereje $e^{8}$ de Vicente Fidel López.

Son obras que amplían narrativamente un tratamiento de la Inquisición que, en las dos que vamos a ver a continuación, se centra en el impulso cultural que

5 J.J. Pesado (1838), El inquisidor de México, México, Planeta/ Joaquín Mortiz, 2002.

6 J. Sierra O'Reylly (1874), La hija del judio, Veracruz, Universidad Veracruzana, 2008.

7 J.P. Alamazán, (1870), Un hereje y un musulmán, México, Porrúa, 1962.

8 V.F. López (1870), La novia del hereje o La Inquisición en Lima, Zaragoza, Ed. La Tinta del Calamar, 2007. 
la Independencia había planteado, en las ideas en definitiva que el Santo Oficio perseguía durante la Colonia y que los autores, en episodios basados en la historia y en los documentos, quisieron ver como anticipo de la libertad que significaba el fin del coloniaje.

\section{Chile y el caso de Francisco Moyen en la novela y la historia}

Cronológicamente, la segunda obra dedicada a la temática inquisitorial es El inquisidor mayor o Historia de unos amores, del chileno Manuel Bilbao, aparecida en Lima en $1852^{9}$. Aunque tendremos que considerar siempre al autor y esta obra dentro de limitaciones estéticas importantes, la atracción que nos crea su novela tiene que ver con el nuevo significado que introduce: aunque temáticamente está centrada a mediados del siglo XVIII, los objetivos que traza en la misma tienen directamente un valor de consolidación de los valores de la Independencia.

Manuel Bilbao es una figura de menor relevancia histórica que su hermano Francisco Bilbao Barquín, auténtico símbolo del liberalismo radical chileno frente a los gobiernos conservadores que se instauraron a partir de 1829 y que los dos hermanos Bilbao combatieron y sufrieron, tras múltiples avatares vivenciales, a partir de 1851, año en el que se produce su exilio obligado a Perú; el señalado es otro de los exilios, diríamos, pues la vida de los dos hermanos está marcada desde la niñez por el exilo de su padre, liberal emigrado en 1829, y tras el regreso a Chile y la publicación por Francisco de Sociabilidad chilena, en 1844, una obra radical y anticlerical, se produce un primer y clamoroso proceso que llevó a Francisco Bilbao a Europa, a París, donde vivirá la revolución de 1848. Manuel Bilbao, nacido en 1827, acompañará en su actividad a su hermano Francisco y será su editor riguroso y devocional tras su muerte en 1865. Algunas obras de Francisco son ejemplares en el intento de consolidar una Independencia real; en sus últimos años, La América en peligro, dedicada a la invasión de México por Francia en 1862, fue una llamada de atención sobre el neoimperialismo europeo. En 1866, al año siguiente de su muerte, nuestro novelista publica en Buenos Aires, en dos volúmenes, las Obras Completas de su hermano: desde los discursos masónicos a sus obras principales (La revolución en Chile, Los mensajes del proscrito, El evangelio americano, junto a las ya citadas).

En el prólogo a la obra, que abre con una biografía de su hermano escrita por él mismo, Manuel dice que pretende con la edición "legar a la posteridad el espíritu del hombre que consagró su vida a la emancipación moral y material de los pueblos (...) La posteridad no olvidará la moral religiosa, civil y social que animó al primero y único que se haya atrevido a ser el iniciador de la emancipación del hombre en América (...) Hacer que esa vida pase a animar con su aliento eterno a los que nos suceden, sembrar el germen de la revolución que

9 M. Bilbao (1852), El Inquisidor Mayor, Charleston, BiblioBazar, 2007. 
debe obrarse en la humanidad, hasta conquistar el reino de la soberanía de la razón en las leyes civiles y religiosas, reino retardado, y combatido por hábitos viciosos y creencias falsas, es nuestro deber, y tal el objeto que nos proponemos al hacer esta edición" 10 .

En el exilio de los dos hermanos en Lima, en 1851, concluye Manuel su novela El inquisidor mayor o Historia de unos amores. Nuestro preámbulo viene aquí porque consideramos que la obra es, por muchas razones, la plasmación en la literatura de lo que hemos resumido brevemente como pensamiento de un símbolo principal del liberalismo chileno: radicalismo, antiimperialismo, anticlericalismo argumentado, consagración de una nueva conciencia que solo se puede basar en la libertad. La condición de novela histórica procede además de que una trama, continuada en varias subtramas, se entrelaza con la utilización de un caso real y documentado de la Inquisición peruana: el del francés Francisco Moyen, acaecido a mediados del siglo XVIII. Como el caso Moyen, modificado y literalizado en la novela, ocupa una parte importante de la misma, nos detendremos inicialmente en el motivo que además, en 1868, fue nuevamente utilizado en un libro por Benjamín Vicuña Mackenna: Francisco Moyen o lo que fue la Inquisición en América ${ }^{11}$, transitado aquí para la polémica contra ataques eclesiásticos y con el rigor del uso explícito de los documentos de un proceso que, entre 1851 (publicación en Lima de la novela de Bilbao) y 1868( publicación en Chile del libro de Vicuña Mackenna), adquiere relevancia y presencia en la literatura chilena y peruana.

Vicuña, figura esencial del liberalismo y de la historia de Chile durante el siglo XIX, utilizó por primera vez el argumento inquisitorial en agosto de 1862, en su discurso de incorporación a la Facultad de Filosofía y Humanidades de la Universidad de Chile ${ }^{12}$. Era una crítica débil de un episodio de conflicto entre, por una parte, el Cabildo Eclesiástico, el Obispado y la Real Audiencia con el Santo Oficio; por otra, en episodios acaecidos desde 1630 a 1639 por una cuestión de supresión de canonjías a beneficio de la Inquisición y luego de apropiación de los bienes de un judío ajusticiado en un famoso Auto de fe de enero de 1639.

La réplica ácida y desmesurada de un canónigo llamado José Ramón Saavedra mediante un libro que quería ser un "panegírico de aquella institución", a la que en sus castigos llama "dulce", lo que es comentado con gran enfado por Vicuña, provocó su obra de 1868, donde "el caso Moyen" se convierte en argumento de polémica y ejemplificación: Francisco Moyen fue un francés "comerciante, músico y pintor”, aprehendido por el Santo Oficio en Potosí en 1749,

10 Obras Completas de Francisco Bilbao, vol. 1, edición hecha por Manuel Bilbao, Buenos Aires, Imprenta de Buenos Aires, 1866, IX.

11 B. Vicuña Mackenna, Francisco Moyen o lo que fue la Inquisición en América (Cuestión histórica y de actualidad), Valparaíso, Imprenta del Mercurio, 1868.

12 Anales, Santiago, Imprenta Nacional, 1862. 
tras la denuncia como hereje, por trece proposiciones sacrílegas, y trasladado a Lima donde, tras un largo proceso y su arrepentimiento, su abjuración de vehementi y su absolución ad cautelam, fue enviado al destierro, a África o a Sevilla. Las trece proposiciones, que hoy imaginamos difíciles de entender hasta para la Congregación de la Fe, tienen un amplio recorrido documental en el libro de Vicuña Mackenna y sustancialmente consisten en que a Dios no hay que temerlo, pues sería vengativo si nos castigase; el hombre está predestinado; la autoridad absoluta del Papa es dudosa; el lujo del clero es escandaloso; los arrieros no pueden maltratar a los animales que son "criaturas de Dios"...junto a otras ideas menos precisas ${ }^{13}$. Los interrogatorios y los dictámenes que van convirtiendo a Moyen en trece veces herético recorren las páginas del libro. De la historia debemos pasar ahora a la novela.

El inquisidor mayor comienza con la llegada de una fragata de guerra española a Lima el 28 de mayo de 1746 en la que viajan el español Rodolfo y la napolitana Magdalena, un joven matrimonio que evocan con tristeza la tierra abandonada. Él había sido nombrado para la judicatura de Lima, tras su formación en París en "la luz de la filosofía producida por los genios que brillaron para la libertad en el siglo XVIII" y, aunque no era "un ciego sectario de los enciclopedistas", aceptaba su fundamento, "la soberanía de la razón". Viaja con ellos Anselmo, un sacerdote franciscano, hermano de Rodolfo, que quiere ir como misionero a la zona del Arauco. El puerto del Callao sume al matrimonio en meditaciones.

La belleza de Magdalena está presente desde el principio en la sociedad limeña, ampliamente descrita en "su obscuridad" cultural y en las fiestas sociales de la nobleza y la administración. En una de ellas, en casa del marqués de Obando, llega el inquisidor mayor, que descubre al anfitrión que ya conoce al matrimonio que ha llegado, y comenta la belleza de Magdalena y el pensamiento bastante libre de su marido. Comienza a partir de aquí una trama amorosa doble: el inquisidor mayor está comprometido en matrimonio con Margarita, una hija de Obando, mientras ha reconocido en Magdalena, cuando era casi una niña, una historia amorosa en un tiempo de Nápoles en el que tuvo que huir y, tras un paso por España, seguir la evasión hasta Lima en donde, protegido por los jesuitas y por su "abate" González (el título es inapropiado), alcanzó la alta responsabilidad. Han comenzado las licencias históricas que debilitan la novela: este inquisidor mayor, laico, comprometido en matrimonio, vive ahora una serie de acontecimientos como el descubrimiento del carácter licencioso de su prometida que, convertida en tapada y, tras una corrida de toros, se encuentra con uno de sus amantes.

Se presenta ampliamente a partir de aquí a la Compañía de Jesús, verdadero objetivo de la denuncia que la novela quiere establecer: el jesuita González tiene una red de informantes, tanto en España como en Lima, que le relatan todo lo

13 Vicuña, op.cit., 71-87. 
que ocurre. Una carta desde la Metrópoli le explica quién es Rodolfo, de familia noble venida a menos y formado en Francia en las "doctrinas ateas", mientras que en conversaciones diarias con sus informantes, otros jesuitas le dan cuenta pormenorizada hasta de las confesiones de personas conocidas. En un encuentro con Magdalena, el jesuita González se da cuenta por las preguntas de ella de que el inquisidor, Eduardo Ramírez, pudo tener alguna relación con la misma en Nápoles y la trama se abre ahora a una visita del sacerdote a la cárcel de la Inquisición. En divagaciones previas se nos relata que cree que debe intervenir contra la posibilidad de que el inquisidor contraiga matrimonio, pues esto perjudicaría a la Compañía de Jesús, ya que no obtendría las rentas que recibe por su actuación en confiscaciones de bienes de los reos, pues irían a su patrimonio. En conversación del jesuita con el inquisidor, se oyen los quejidos por la tortura que se está aplicando a Moyen y sabemos que ha sido denunciado por González cuya crueldad se manifiesta en pedir que siga el suplicio. El jesuita recomienda al inquisidor que se olvide de sus propósitos matrimoniales para servir mejor a Dios. El recorrido por la cárcel secreta le permite ver a otros presos hasta que, al llegar a Moyen, comentan que tenía una enamorada, Enriqueta, a la que desvió de su vocación de ser monja.

Una prolija narración de episodios sigue ahora: el padre Anselmo, hermano de Rodolfo, se va desde El Callao a su misión en Arauco; el engaño de Margarita que, como tapada, se encuentra con un amante, llamado Salazar, tras una corrida de toros, y cómo, al conocerlo el inquisidor hace que este sea llevado a la cárcel secreta; el encuentro del inquisidor con Magdalena a la que cuenta sus desventuras napolitanas y su historia y la afirmación de fidelidad al marido por parte de esta; los consejos del jesuita para que el inquisidor vuelva a Magdalena (para romper definitivamente su relación con Margarita y evitar cualquier posibilidad de matrimonio).

A partir del capítulo XV, el proceso de Moyen centra de nuevo la novela que narrativamente contiene tramas tan dispares: recibimos la información de que, aparte de haber vertido proposiciones irreligiosas, no profesa culto conocido, acusa de inmoral la esclavitud de los negros y afirma que su conducta solo se deja guiar por la razón. Largos episodios narran ahora los intentos para que se arrepienta de su herejía, para lo que se recurre en primer lugar a un fraile. Un largo debate (cincuenta páginas de la edición que manejo en cuatro capítulos), en el que Moyen afirma su cristianismo, pero niega que sea católico, abre la primera parte repleta de varias intervenciones del fraile y respuestas del reo. Argumenta Moyen que no es católico, entre otras razones, porque a la igualdad el catolicismo opuso jerarquías, sancionando como de origen divino la soberanía de los reyes; tampoco lo es porque a la doctrina del amor opuso la violencia, y la prueba es la Inquisición; y ya, en deriva política directa, "a la libertad de conciencias, a la libertad política"la combatió con "la abdicación de la razón, y apoyó el despotismo de los monarcas". Las réplicas del fraile, repletas de autoridad y autoritarias, no 
sirven para nada: el hombre se salva por la fe y "no hay crimen mayor que pensar libremente". Tras largos y cansados argumentos, aplazan el debate al día siguiente, donde el relato asume al principio la presentación de las ideas de Moyen como lector de Voltaire, Rousseau y Diderot; también su belleza física reducida por la tortura casi a un cadáver. Sigue el debate, con afirmaciones de la propia conciencia y ataques al Santo Oficio, hasta que las respuestas del fraile le llevan a afirmar que ellos, los católicos, son los destructores "de la más bella creación de Dios, la razón", los asesinos del espíritu que tiene su ideal "en la aspiración constante del alma a buscar lo bello, la verdad a través de los mundos que ruedan en el infinito". Y tras el Moyen liberal de la primera serie, oímos ahora al Moyen masónico, iluminando cuando dice esto "sus ojos con una centella de ardor". El fraile lo insulta llamándole "hijo del infierno", entre otras lindezas; rompen el diálogo y Moyen, al sentirse injuriado, concluye arrojándole, cuando sale, la jarra de agua, lo que provoca que el fraile desista de cualquier otro intento.

Sigue - ya estamos en el capítulo XVII- un nuevo intento de conversión por parte del propio jesuita Rodríguez: dialogan ahora sobre la esclavitud de los negros, defendida por el sacerdote, y negada por Moyen que afirma como inalienable la libertad y, además — nos dice - la esclavitud beneficia a "los capitalistas", pero perjudica a la industria pues trabaja más y mejor un hombre libre... al ser irreductible en sus posiciones, le plantea que en algunas cosas están de acuerdo, y le sugiere que finja la conversión a todo lo que se le pide, pero el reo afirma que no está dispuesto al engaño...para dulcificarlo, el jesuita se despide y le dice que intentará que le quiten los grillos y le den bien de comer. El carcelero se sienta con él y le cuenta la triste historia que le llevó a su trabajo.

$\mathrm{El}$ segundo encuentro con el jesuita, a las nueve de la mañana del siguiente día, trata sobre la oposición entre razón y fe, aunque Moyen defiende las dos en terrenos diferentes. La infalibilidad del Papa es puesta en discusión por el francés que propugna un cambio de orden social y afirma en un momento la posibilidad de la anarquía. Escandalizado, el clérigo le anuncia la condena y la hoguera, ante lo que Moyen responde que morirá "dando testimonio de la verdad".

"Una sesión secreta del tribunal de la Inquisición" es el capítulo XX que comienza con el juicio "privado" a Salazar — amante de Margarita, encarcelado vengativamente por el inquisidor, que ha obligado a estar presentes a esta y a su madre-, mientras el XXI está dedicado al juicio "público" a Moyen. Está presente Rodolfo entre el público, autorizado por su condición de miembro de la judicatura: defiende Moyen una y otra vez la libertad del pensamiento y la conciencia, hasta que es silenciado por el inquisidor. En un momento previo, de entre un público que pide a gritos el castigo del hereje se levantan dos dominicos para agredir al reo, lo que es impedido por Rodolfo al que el inquisidor ordena que se siente. Concluye el juicio tras el desalojo de la sala y el tribunal pronuncia su sentencia condenatoria. 
La continuidad de la trama se hace ahora difícil: el inquisidor rompe con Margarita; Enriqueta, la novia de Moyen, llamada en el título de un capítulo "la novia del hereje", inicia, ayudada por Magdalena, un intento de salvar a su prometido, en el que llegan hasta al Virrey. El inquisidor persigue ahora a Magdalena sin éxito y, al conocerlo, es retado en duelo por Rodolfo, por lo que este ordena que le detenga la Inquisición y, sin mediar mucha historia, enviado en un barco desde El Callao a las cárceles de Sevilla. Se inicia un nuevo episodio en el que Magdalena, sin saber donde está Rodolfo, lo busca, encuentra papeles que comprometen al inquisidor, media hipócritamente el jesuita González y va, junto a Enriqueta, a pedir ayuda al Virrey, "sometido a la Compañía de Jesús", como dice el título del capítulo XXIX. El jesuita se hace con los papeles de Magdalena mediante engaño. El reo Moyen entra en capilla y en el capítulo XXXI es ajusticiado en un Auto de fe. Enriqueta se ha vuelto loca y observa desde una ventana el paso del sambenitado. Eduardo hace un intento de aproximarse a Magdalena que sigue dudando de él y el jesuita utiliza un Cristo de la sala del Santo Oficio, cuya cabeza mueve el inquisidor afirmativamente, para resolver que son mentiras las dudas de Magdalena. La locura de Enriqueta, sus delirios y sueños; la muerte de Margarita a manos de Eduardo al que con engaño ha intentado reconquistar y encerrar en un caserón; la muerte de Enriqueta en el convento de las Claras se produce al 28 de octubre de 1746 cuando el terremoto de Lima y la destrucción de El Callao parece un castigo divino. En el relato de la catástrofe, el inquisidor salva a Magdalena de morir...la historia ya solo se puede cerrar con un Epílogo breve mediante el que sabemos que Magdalena decide ir a Chile a buscar al franciscano Anselmo, aunque Eduardo, el inquisidor, se embarca en el mismo viaje...mientras el jesuita González, muy molesto, lo cesa como inquisidor y nombra a otro "devoto de la Compañía".

La historicidad del relato, alterada fuertemente en el caso Moyen, con la ampliación abrumadora de los interrogatorios y la conclusión con el inexistente Auto de fe y ajusticiamiento; la historicidad comprometida con detalles importantes como la imposible condición laica del inquisidor mayor, o la fusión de la peripecia inquisitorial de Rodolfo con el destierro real de Moyen; o los episodios entremezclados como el terremoto de Lima, junto a toda la red tejida por el llamado abate González (que no podía ser abate) y la Compañía de Jesús...podrían haber sido creados en función de la ficción literaria, pero funcionan inversamente a esta, debilitándola en extremo, restando valor a la historia y el relato. La importancia de la obra no puede estar entonces en sus valores literarios o históricos, que nos parecen muy débiles, sino en el proyecto ideológico que Manuel Bilbao mantuvo en su escritura: la denuncia de la sociedad colonial y la afirmación de una serie de tipos humanos (el Moyen real, el protagonista Rodolfo...) que indicaban la nueva sociedad que había surgido tras la Independencia, o la que, a cuarenta años de su primer desarrollo, un radical del liberalismo, anticlerical y antijesuita en su condición masónica, quería que surgiese. 


\section{Guillén de Lampart y su recreación literaria}

Guillén de Lampart, Guillermo Lombardo, o Guillermo Lamport, según es llamado variablemente en los documentos, es, sin duda, unos de los casos más enjundiosos del relato inquisitorial en el México del siglo XVII, en cuanto asume valores históricos, ideológicos y narrativos que lo sacan del perfil habitual de un condenado, y ejecutado en un Auto de fe en 1659, hacia una intriga desmesurada e inquietante.

Sobre quién fue este irlandés afincado en México en 1640, sigue siendo esencial la síntesis creada por José Toribio Medina ${ }^{14}$, basándose sobre todo en documentos de la Inquisición y en el testimonio de quien fue encargado de la defensa de Lampart y de otros ajusticiados con él, Rodrigo Ruiz de Cepeda Martínez, quien publicó una justificación imprescindible del Auto de fe ${ }^{15}$. Su presencia en estas páginas procede además de su conversión en personaje de novela por $\mathrm{Vi}$ cente Riva Palacio ${ }^{16}$ y por la reinterpretación del pretendido independentismo del personaje realizada por Luis González Obregón a comienzos del siglo XX ${ }^{17}$. Su vida, contada pormenorizamente a los inquisidores y repleta de invenciones, es la de alguien nacido en Irlanda hacia 1613 que llegó a México, tras varias aventuras intelectuales y políticas en su país y en España, y fue denunciado ante el Santo Oficio por un capitán llamado Felipe Méndez en 1642, a quien había comunicado que el año siguiente tenía preparado todo para convertirse en Rey mediante una insurrección, liberando a los indios y mestizos, y a los esclavos negros; que contaría para esto con el favor del rey de Francia y del Papa; que estaba emparentado con la familia real española y era hermano de Felipe IV e hijo natural por tanto de su padre Felipe III; que tenía contactos con un indio que era hechicero para asegurarse la empresa...

Tras la detención, dará cuenta de su rigurosa formación, de las lenguas que hablaba, de los servicios que había realizado a la monarquía española, que le había honrado con dádivas y reconocimientos; también de sus contactos con el Rey, con el Conde Duque de Olivares y con el cardenal Richelieu.

Había venido a México en la misma nave que trajo en 1640 al nuevo virrey don Diego López Cabrera, marqués de Villena, y al obispo de Puebla, don Juan de Palafox y Mendoza, pero como viajero ínfimo de la servidumbre del virrey

14 J. T. Medina, Historia del tribunal del Santo Oficio de la Inquisición en México, ampliada por Julio Jiménez Rueda, México, Ediciones Fuente Cultural, 1952, 255-266. La primera edición fue en 1905 en Chile. Utilizo la de México, anotada por Jiménez Rueda, como base principal de la biografía resumida.

15 R. Ruiz de Cepeda Martínez, Auto general de la Fe que asistió en nombre y representación de la católica majestad... celebrado en la Plaza Mayor de la muy noble y muy leal ciudad de México a los 19 de noviembre de 1659, México, Fernando Calderón, 1660.

16 V. Riva Palacio, Memorias de un impostor: don Guillén de Lampart, rey de México, México, Porrúa, 1946.

17 L. González Obregón, Don Guillén de Lampart, La Inquisición y la Independencia en el siglo XVII, París/México, Librería de la Viuda de C. Bouret, 1908. 
y sin contacto con ellos. La situación desastrosa del virreinato, las tensiones e intrigas políticas que llevaron al cese del virrey y su sustitución por el obispo Palafox, contribuyeron a que Lampart trazara su plan que partía de que los soberanos españoles no tenían derecho al dominio de América, pues el Papa que se lo había otorgado no detentaba, como ninguno de ellos, potestad temporal. La liberación de los esclavos y vasallos en general haría que lo aceptasen como rey, para lo que preparó cartas reales, con sellos falsificados, que lo nombraban a él como marqués de Cropali y virrey, lo que, tras ser comunicado a la Audiencia para que le apoyasen, iniciaría la rebelión, que, al triunfar, tomaría medidas entre las que establecía el libre comercio de México con otros países, prohibiendo el de España y su monopolio, el envío de embajadores (a Roma, Francia, Venecia, Portugal e Irlanda); también liberaría a los esclavos; sirviéndose de los que le hubiesen ayudado, crearía un Consejo de Hacienda y un Consejo Real para una nueva administración; anularía la obligatoriedad de los impuestos a todos los ciudadanos.

Un documentado expediente inquisitorial con alegatos, textos con citas clásicas, poemas, nutrieron diez años de persecución y un aviso de prudencia por parte de la Metrópoli, de la Suprema de la Inquisición. Siguió una fuga desde la cárcel de la Inquisición ya en 1650, en la que llenó varios lugares de pasquines acusatorios contra las figuras eclesiásticas que lo perseguían, haciendo llegar además una carta al virrey Conde de Alba para que prendiera como traidores a los inquisidores. Los edictos que lo perseguían, con graves amenazas para quien lo protegiera, lo llevan nuevamente a las cárceles secretas, donde varios religiosos intentan su arrepentimiento. Escribió entonces un memorial contra la Inquisición, un tratado en versos latinos...síntomas de locura, apariciones de demonios, acusaciones de herejía, silencio absoluto a veces, llevan a la condena y a la muerte en el Auto de fe de 1659, en el que, según cuenta el testigo Ruiz de Cepeda “... dio a entender desde la noche antecedente que el demonio su familiar le había de socorrer, fue por las calles mirando hacia las nubes si venía aquella fuerza superior que aguardaba; y poniéndole sentado para el suplicio, y fijándole la garganta con una argolla, viendo que sus esperanzas le habían salido vanas, y engañado del demonio, él mesmo se ahogó dejándose desesperado caer de golpe, y en breve se convirtió en cenizas aquel hombre infernal"18.

Vicente Riva Palacio, cuyo material narrativo principal fue la Inquisición, lo convirtió en personaje de novela. Explicaba el autor su actividad: “¿por qué en la mayor parte de mis novelas hablo de la Inquisición? Te contestaré que en toda la época de la dominación española en México, apenas puede dar el novelista o el historiador un solo paso sin encontrarse con el Santo Tribunal, que todo lo abarcaba y todo lo invadía; y si encontrártelo en una novela te causa disgusto, considera qué les causaría a los que vivieron en aquellos tiempos, encontrar al Santo

18 Cit. por Medina, op.cit., 266. 
Oficio en todos los pasos de su vida, desde la cuna hasta el sepulcro, desde la memoria de sus ascendientes hasta el porvenir de su más remota generación"19.

La ficción y la historia adquirieron una fusión complicada, no compleja, en la obra del general Riva Palacio, cuyo papel político y militar le llevó a tener muy cerca, en su propio domicilio, los documentos inquisitoriales que nutrieron una parte de su obra: su novela más difundida, la extensa Monja y casada, Virgen y Mártir ${ }^{20}$ incrementa el espacio ficcional, mientras una reconstrucción documental había dado cuenta de la persecución a una familia notable acogida a la ley de Moisés, La historia de la familia Carabajal. Un tétrico y abominable caso de la Santa Inquisición en México.

Monja y casada..., escrita en 1868, es una trama irresumible de amores, venganzas, familias criollas en 1615, y odios entre las mismas, figuras del poder virreinal como el virrey Gelbes, fanatismo, arzobispo corrupto, ejecuciones de esclavos negros en el Auto de fe de 1632, a través de una trama que confluye en el libro cuarto y último en una novela de la Inquisición, con la narración de los suplicios a los que es sometida Blanca (personaje basado en un proceso real, el de "la llamada Blanca de Mejía en el siglo o sor Blanca del Corazón de Jesús, profesa en el convento de Santa Teresa...”, según transcribe en la novela Riva Palacio desde un documento inquisitorial) y cuya sustitución por la malvada Luisa, la mulata (personaje representativo de maldad, intriga y amores múltiples a lo largo de toda la obra) le permite salvarse, mientras el conjunto de más de ochocientas páginas es, en los tres libros primeros y como dice el subtítulo de la obra, "una historia de los tiempos de la Inquisición", con pasos varios de personajes por sus cárceles secretas.

Otra novela de Riva Palacio, Martín Garatuza ${ }^{21}$, que continúa a Monja y ca$s a d a$, se construye con referencia precisa a un caso inquisitorial y utiliza el personaje real que da título a la obra y que ya había aparecido en la primera: los judíos adquieren papel relevante a través de la figuras de doña Juana de Carvajal y su hija Esperanza, descendientes de familia perseguida y ajusticiada por la Inquisición, pero varias tramas, entre ellas la principal de Martin Garatuza, crean una novela caótica y de difícil lectura.

En 1872, Memorias de un impostor: don Guillén de Lampart, rey de México, fue escrita con dos amplios volúmenes documentales de más de mil páginas delante de los ojos, pero incrementando el espacio ficcional al construirla sobre todo a través de una trama amorosa, bastante delirante, en la que Guillén de Lampart es presentado entre enredos sentimentales y eróticos múltiples que lo llevan a estar vinculado a cinco mujeres en ficción duradera que ocupa casi totalmente el primer volumen de la obra.

19 V. Riva Palacio, Memorias..., vol. I, "Prólogo del autor", XV.

20 V. Riva Palacio, Vicente (1868), Monja y casada, virgen y mártir. Historia de los tiempos de la Inquisición, México, Editora Nacional, 1958.

21 V. Riva Palacio (1868), Martín Garatuza, México, Conaculta/Planeta Agostini, 2004. 
Un espantoso huracán y un incendio en el centro de la ciudad de México abren la novela, que se despliega en una serie de acontecimientos que tienen que ver con las relaciones de Guillén de Lampart: destaca en primer lugar la familia Méndez, a la que el protagonista salva de un incendio y les consigue recuperar una misteriosa caja; sobresale también la figura de doña Juana Henríquez, realmente Rebeca la judía, con quien Guillén mantiene relaciones. Una de las tramas inmediatas será el origen de la caja que va a parar a manos del protagonista y que contendrá planos del tesoro de Moctezuma lo que es valorado en una sociedad conspirativa llamada Urania, en la que se reúnen un grupo de nobles y señores principales que quieren la independencia de México y nombrar virrey a Lampart (enigma que ocupa todo el "Libro primero", titulado "Los misterios de Urania").

Las intrigas de un caballero llamado Martín de Malcampo para conseguir a doña Juana se unen a las maquinaciones del virrey que también quiere convertirla en su amante. Malcampo sabe que doña Juana-Rebeca es judía y que su familia practica el judaísmo, reuniendo su padre, don Gaspar, en su casa a los judíos principales de México. Malcampo se presta, para conseguir favores, a que doña Juana vaya a manos del virrey para lo que amenaza a ella y a su padre en desvelar a la Inquisición su condición de judíos.

La figura de Palafox y Mendoza nutre otra intriga, real en la historia, como es la deposición de virrey y su proclamación como tal por acuerdo de la corona. Una larga confabulación que se completa la misma noche que el virrey debía encontrarse con doña Juana (Riva apuesta contra Palafox en la conjura por el pretendido apoyo del virrey al duque de Braganza, que pretendía hacerse rey de Portugal).

Felipe Méndez, el hijo de la familia que Lampart había salvado del incendio en los primeros episodios, quiere conseguir a otra de las amantes de este, doña Inés: para hacerlo trama que ella sepa que es una mujer más en la vida del caballero irlandés. Consigue para ello que todas, doña Juana, Inés, Carmen, Clara... coincidan en un mismo lugar al que también ha convocado a don Guillén. La desilusión de todas es grande y doña Inés se irá con Felipe sin saber que, al mismo tiempo, este ha denunciado a don Guillén a la Inquisición, lo que hace comenzar la trama principal de la novela.

Es ahora la vida de don Guillén en la Inquisición en los siete primeros años de aquel proceso, sus objetivos de liberación de México, su manifestación de locura, su pasado contado a un compañero de cárcel (su tiempo inicial en Inglaterra, su lucha mediante un libelo contra el rey, su vida como pirata, sus estudios en España, sus servicios a la corona española); sigue la preparación, minuciosamente narrada en la obra, de la fuga, que el propio Riva destacaba: "La evasión de don Guillén y las circunstancias que la acompañaron, en nada cede por lo interesante, lo bien combinada y lo audazmente ejecutada, a esas romancescas evasiones que nos cuentas los novelistas franceses" 22 , y efectivamente no está lejos

22 V. Riva Palacio, Memorias..., vol. I, "Prólogo del autor", XV. 
sobre todo de la famosa de El conde de Montecristo, siendo Alejandro Dumas un modelo seguro de Riva Palacio 23 .

Continúa con el episodio de los pasquines contra sus perseguidores y la carta al virrey contra el Santo Oficio; en lo referente a los pasquines, el novelista transcribe en varias páginas uno de los documentos pegados en las paredes de la catedral en el que violentamente denuncia a los inquisidores por su corrupción económica (por eso persiguen a los judíos) y su invención de cargos y falseamiento de testigos.

A los dos días se produce su nueva captura, a la que siguen los años de nuevo encierro, enmarcados en su "Desesperación" que es el título del capítulo III de la cuarta parte, la final, de la obra: cambios de estado de ánimo de don Guillén, que escribe papeles, unas veces llenos de insultos y otras de alabanzas a los inquisidores y al Santo Oficio; poemas de los que se transcribe algún ejemplo, síntomas de lo que el novelista califica como locura. Su condena a muerte tras diecisiete años en las cárceles inquisitoriales cierra esta parte y abre la ejecución, apareciendo la larga trascripción de la sentencia y la ejecución como Apéndice de la novela

El momento final, el Auto de fe del 18 de noviembre de 1659, esta visto desde la casa que ocupan don Felipe Méndez, su denunciante, y doña Inés, con la que vive tras conseguirla después de la trampa en la que don Guillén se encontró con todas sus mujeres. Cuando el preso sambenitado pase por delante de la ventana de doña Inés, un cruce de miradas demostrará a don Felipe que ella todavía lo ama. También lo comprenderá don Guillén antes de llegar al Quemadero y ser ajusticiado. Cuando echen las cenizas de los ajusticiados a una acequia, doña Inés, cuya mirada no ha dejado a don Guillén mientras vive, clava una daga en el corazón de don Felipe y se lanza al agua que ha acogido a su antiguo amor. Y desaparece en el canal.

Un epílogo cierra aún el episodio: Clara, una de las antiguas enamoradas por don Guillén, la hija de la familia a la que salvó del incendio en el primer capítulo, recibe en el convento en donde está, por comunicación de un fraile, la noticia de que Guillén está siendo conducido para ser ajusticiado y la monja muere al saberlo...

El resumen que antecede puede servirnos para comprobar la debilidad de la obra, cuya trama tiene más valor, si llega a tenerlo, en lo referente a los enredos amorosos inventados a través de la figura de don Guillén de Lampart: la sociedad Urania, inventada por Riva Palacio, junto a la persecución inquisitorial, seguida como segunda trama por los documentos que manejaba el novelista, nos ponen delante un valor del personaje que el siglo XIX acrecentó en cuanto símbolo de la Independencia: su presencia en escultura entre los padres

23 Lo plantea, en un interesante artículo, José Joaquín Blanco, "Los misterios de don Guillén de Lampart”, http://sociedadlatinoamericana.bligoo.com/content/view/810097/Los-misteriosde-don-Guillen-de-Lampart.html (consultado 12/9/2011). 
de la misma ${ }^{24}$, su uso literario posterior en la creación del personaje de E1 Zo$\mathrm{rro}^{25}$, son valores añadidos a la reinterpretación de la historia que hizo Manuel Riva Palacio.

Luis González Obregón intentaba atenuar este valor, cuarenta años después de la novela, cuando don Guillén de Lampart había entrado sin duda gracias a la misma en el imaginario independentista: combatió la idea de la estatua, que por fin se hizo, e insistió en que Lampart era un megalómano, enloquecido por las torturas, cuyo atractivo principal fue su juventud aventurera, su cultura, su ingenio, y su sufrimiento a manos del poder inquisitorial, pero que nunca podría considerársele un precursor de la Independencia.

\section{Para reinventar la Independencia}

La idea es bastante sencilla: Manuel Bilbao y Vicente Riva Palacio seleccionaron un material documental e histórico para crear sus novelas, y lo acomodaron, variaron y reinventaron (más evidente el procedimiento de ampliación de la historia en Manuel Bilbao que en la ficcionalización amorosa del personaje realizada por Riva Palacio) para hacerlo coincidir con los objetivos de una novela independentista que no había aparecido hasta este momento sobre episodios sustanciales de la historia. Parece que la ausencia documental de las ideas de la misma Independencia, hasta de una claridad sobre la ideología que la sustentó en los diferentes países, animaba a rastrear las posibilidades del pensamiento ilustrado en el caso de Bilbao, o de un independentismo avant la lettre en el caso de Riva Palacio.

Se basaban en retazos de historia y en la modificación de los mismos mediante tramas que hoy resultan algo delirantes, pero abrían un camino de creación que, si en el siglo XIX fue breve, en el XX se desplegará en otras muchas creacione ${ }^{26}$ en las que la materia literaria sobre la Inquisición sirvió para crear

24 Un polémica permanente, desde la inauguración del Monumento a los Héroes de la Independencia (El Ángel) en 1910, hasta el Bicentenario, ha acompañado la presencia de Guillén de Lampart en el interior del mismo. A partir de 2010 ha estado muy presente en la prensa y la sociedad mexicana.

25 La relación entre el personaje, a través de la novela de Riva Palacio, y don Diego de Vega, "E1 Zorro" de Johnston McCulley, quien en 1919 lo creó inaugurando una larga saga, está bien contada por J. Soler en "Los orígenes de E1 Zorro", El Pais, 27/11/2005, http://www.elpais.com/ articulo/portada/origenes/Zorro/elpeputec/20051127elpepspor_5/Tes (consultado 3/8/2011).

26 Hay en los últimos decenios una abundante recreación del tema inquisitorial en la narrativa hispanoamericana: el arco temporal es amplio, desde G. Espinosa, Los cortejos del diablo, Montevideo, Alfa, 1970, y del mismo G. Espinosa, La tejedora de coronas, Bogotá, Alfaguara, 1982, a G. Frías, El inquisidor. Un origen para la leyenda. Santiago, Alfaguara, 2008. Entre otros, considero como modelos principales o a los que hay que prestar atención: G. Blanco (1989), Camisa limpia, Santiago, LOM, 2008; M. Aguinis (1991), La gesta del marrano, Buenos Aires, Planeta, 2003; S. Bossio Suárez, El llanto en las tinieblas, Lima, Biblioteca de Narrativa Peruana Contemporánea, 2002. También existen intentos de bestseller de regular entidad: E. Cárdenas, Mi vasallo más fiel. Pasiones y pecados de un inquisidor en la Nueva España, México, Planeta, 2002, E. Serna, Ángeles del 
metáforas sociales, no ya sobre la Independencia, sino sobre la libertad, pero esto es tema de otros enfoques y trabajos en curso $^{27}$.

Mucho han envejecido sin duda las dos obras tratadas, que podríamos someter a un debate sobre su historicidad, sobre su misma condición de novelas basadas en la historia, en las que se aplica una ficción, alterando lo documental, para hacer funcionar los episodios del pasado como narraciones literarias con función ideológica hacia el presente.

Lo que nos queda de ellas es el valor de dos personajes reales, con aporte documental importante, para reinterpretarlos en la historia, para rehacer con ellos los sentidos de la misma, en función determinante que quería construir una sociedad nueva en la que era necesario insistir sobre que el pasado tenía ejemplos que daban densidad al presente y que estaban vinculados al hecho crucial de la emancipación.

\section{BIBLIOGRAFÍA}

Aguinis, M. (1991), La gesta del marrano, Buenos Aires, Planeta, 2003.

Alamazán, J. P. (1870), Un hereje y un musulmán, México, Porrúa, 1962.

Bilbao, F., Obras Completas de Francisco Bilbao, vol. 1, edición hecha por Manuel Bilbao, Buenos Aires, Imprenta de Buenos Aires, 1866.

Bilbao, M. (1852), El Inquisidor Mayor, Charleston, BiblioBazar, 2007.

Blanco, G. (1989), Camisa limpia, Santiago, LOM, 2008.

Bossio SuÁrez, S., El llanto en las tinieblas, Lima, Biblioteca de Narrativa Peruana Contemporánea, 2002.

CÁrdenas, E., Mi vasallo más fiel. Pasiones y pecados de un inquisidor en la Nueva España, México, Planeta, 2002.

Delibes, M., El hereje, Barcelona, Destino, 1998.

Espinosa, G., Los cortejos del diablo, Montevideo, Alfa, 1970.

—, La tejedora de coronas, Bogotá, Alfaguara, 1982.

FríAs, G., El inquisidor. Un origen para la leyenda, Santiago, Alfaguara, 2008.

García Márquez, G., Del amor y otros demonios, Barcelona, Mondadori, 2004.

González Obregón, L., Don Guillén de Lampart, La Inquisición y la Independencia en el siglo XVII, París/México, Librería de la Viuda de C. Bouret, 1908.

abismo, México, Seix Barral, 2004; P. Sturlese, El inquisidor, Barcelona, Randon House Mondadori, 2007. Hay otras novelas con referencia inquisitorial importante como la de P. Orgambide, Aventuras de Edmund Ziller, Buenos Aires, Ed. Abril, 1984; también la de G. García Márquez, Del amor y otros demonios, Barcelona, Mondadori, 2004; también, conjuntos de relatos como los de F. Iwasaki, Inquisiciones peruanas, Sevilla, Renacimiento, 2007. En la literatura española, debemos pensar en M. Delibes, El hereje, Barcelona, Destino, 1998, o la muy reciente de L. Silva, El blog del inquisidor, Barcelona, Destino, 2008.

27 "Inquisición y novela en Latinoamérica: el pasado y las nuevas posibilidades narrativas" y "Sobre novelas, reos e inquisidores", en C. Gómez Carlo y E. Maldonado, eds., Ficción y realidad en América Latina, México, Universidad Nacional Autónoma de Azcapotzalco, 2011, 15-22, están basados en el análisis de otros modelos. 
IwASAKi, F., Inquisiciones peruanas, Sevilla, Renacimiento, 2007.

López, V. F. (1870), La novia del hereje o La Inquisición en Lima, Zaragoza, Ed. La Tinta del Calamar, 2007.

Medina, J. T., Historia del Tribunal del Santo Oficio de la Inquisición en México, ampliada por J. Jiménez Rueda, México, Ed. Fuente Cultural, 1952.

Olaechea, R., "Francisco Miranda y la Inquisición española: el Santo Oficio como instrumento de la política de Estado", C.I.H. Brocar, no 13, 1987, 29-56.

Orgambide, P., Aventuras de Edmund Ziller, Buenos Aires, Ed. Abril, 1984.

Pesado, J. J. (1838), El inquisidor de México, México, Planeta/ Joaquín Mortiz, 2002.

Riva Palacio, V., Memorias de un impostor: don Guillén de Lampart, rey de México, México, Porrúa, 1946.

- (1868), Monja y casada, virgen y mártir. Historia de los tiempos de la Inquisición, México, Editora Nacional, 1958.

- (1868), Martín Garatuza, México, Conaculta/Planeta Agostini, 2004.

Rovira, J. C., "Sobre novelas, reos e inquisidores”, en C. Gómez Carlo y E. Maldonado, eds., Ficción y realidad en América Latina, México, Universidad Nacional Autónoma de Azcapotzalco, 2011, 15-22.

Ruiz de Cepeda Martínez, R., Auto general de la Fe que asistió en nombre y representación de la católica majestad... celebrado en la Plaza Mayor de la muy noble y my leal ciudad de México a los 19 de noviembre de 1659, México, Fernando Calderón, 1660.

Serna, E., Ángeles del abismo, México, Seix Barral, 2004.

Sierra O'Reylly, J. (1874), La hija del judio, Veracruz, Universidad Veracruzana, 2008.

Silva, L., El blog del inquisidor, Barcelona, Destino, 2008.

Sturlese, P., El inquisidor, Barcelona, Randon House Mondadori, 2007.

Vicuña Mackenna, B., Francisco Moyen o lo que fue la Inquisición en América (Cuestión histórica y de actualidad), Valparaíso, Imprenta del Mercurio, 1868.

-, Anales, Santiago, Imprenta Nacional, 1862. 
